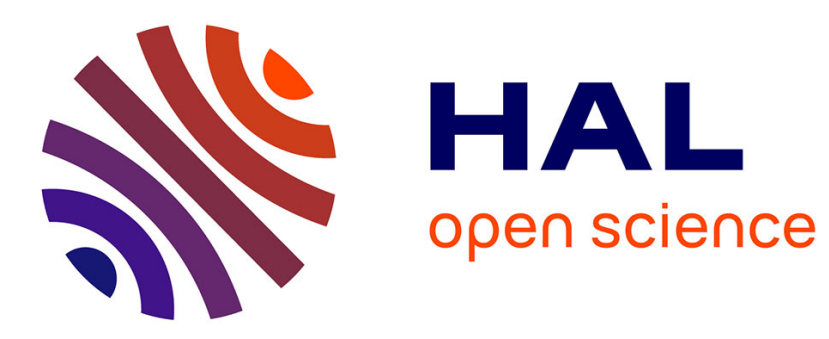

\title{
Part-of relations, functionality and dependence
}

\author{
Laure Vieu, Michel Aurnague
}

\section{To cite this version:}

Laure Vieu, Michel Aurnague. Part-of relations, functionality and dependence. Michel Aurnague; Maya Hickmann; Laure Vieu. The categorization of spatial entities in language and cognition, 20, John Benjamins Publishing Company, pp.307 - 336, 2007, Human Cognitive Processing, 97890272 2374 6. 10.1075/hcp.20.18vie . hal-01078739

\section{HAL Id: hal-01078739 https://hal.science/hal-01078739}

Submitted on 30 Oct 2014

HAL is a multi-disciplinary open access archive for the deposit and dissemination of scientific research documents, whether they are published or not. The documents may come from teaching and research institutions in France or abroad, or from public or private research centers.
L'archive ouverte pluridisciplinaire $\mathbf{H A L}$, est destinée au dépôt et à la diffusion de documents scientifiques de niveau recherche, publiés ou non, émanant des établissements d'enseignement et de recherche français ou étrangers, des laboratoires publics ou privés. 


\title{
Part-of Relations, Functionality and Dependence
}

\author{
Laure Vieu ${ }^{\mathrm{i}, \mathrm{ii}}$ and Michel Aurnague $\mathrm{iii}^{\mathrm{iii}}$ \\ ${ }^{\mathrm{i}}$ Institut de Recherche en Informatique de Toulouse (IRIT-UMR 5505) \\ CNRS, Université Paul Sabatier, INPT \& UTI

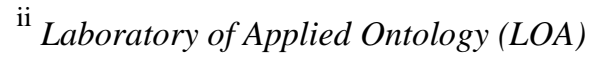 \\ ISTC-CNR, Trento (Italy) \\ ${ }^{\mathrm{iii}}$ Equipe de Recherche en Syntaxe et Sémantique (ERSS-UMR 5610) \\ CNRS \& Université de Toulouse-Le Mirail
}

\section{Introduction ${ }^{1}$}

Constructions referring to part-whole relations are quite usual in language:

(1) Ma main fait partie de mon corps.

('My hand is part of my body.')

(2) la poignée de la porte ('the handle of the door')

(3) le haut de l'armoire ('the top of the cupboard')

(4) Ce plat est constitué de poivrons et de morue.

('This dish is made up of pepper and cod.')

(5) Cet atome a un électron. ('This atom has an/one electron.')

Genitive constructions with (3) or without (2) "relational nouns" play an important role in the expression of part-whole relations (Barker, 1995; Partee \& Borschev, 2003). This paper mainly focuses on such constructions 
as well as on several well-known structures like Det Npart est une/fait partie de Det Nwhole ('Det NPpart is (a) part of Det Nwhole') (1) or Det Nwhole a un Det Npart ('Det Nwhole has a Det Npart') (5) which have been already addressed in other works on part-whole relations (Cruse, 1986; Winston et al., 1987; Iris et al. 1988; Pribbenow, 1995; Tamba, 1994). However, the constructions calling, to some or other extent, to part-whole relations are much more numerous and varied (4). ${ }^{2}$ Such a large range of expressions illustrates the importance of part-whole relations in language.

As we will see in next section, a semantic analysis of these kind of structures shows that language makes sharp distinctions among part-whole relations. This paper proposes a formal analysis of the semantics of the partwhole relations distinguished by language and shows, at the same time, that these relational distinctions heavily rely on distinctions among entities, more precisely on ontological and linguistic categories of entities.

Besides the restrictions on linguistic constructions addressed in this work, additional constraints apply to the entities and configurations considered. We will limit ourselves to the study of descriptions that involve "spatial entities", i.e., spatially extended entities and especially, material objects.

A particular attention will be paid to the inferential properties of our formal proposal which is supposed to account for the deductions linguistically expressed. More generally, we make the assumption that the part-whole relations distinguished by language and the theory built for representing their semantics have a wider cognitive grounding and validity. 
Previous semantic analyses and formalizations already exist for some partwhole relations in linguistics, cognitive psychology, and philosophy, but curiously, for the "main" part-whole relation — the one involved in (1), (2) and (5) above, the existing proposals are very sketchy at best and puzzles regarding its inferential behavior remain unsolved. As a result, this work is mainly dedicated to this relation and the underlying notion of "functional dependence".

\section{The multiplicity of part-whole relations}

As the expression of part-whole relations in language appears quite diverse, it is legitimate to investigate whether different kinds of expressions refer to a single relation or to several ones.

From a linguistic point of view, the selectional restrictions induced by "generic" part nouns (e.g., partie ('part'), bout ('piece', 'bit'), constituant ('constituent'), composant ('component'), élément ('element', 'member'), fragment ('fragment'), membre ('member'), ingrédient ('ingredient')) are not homogeneous (Iris et al., 1988; Aurnague, 2004). This would indicate a variety of relations, to which also points the complex distribution of some genitive markers (e.g, possessive and locative genitives of Basque) (Aurnague, 2002). 
On the other hand, logical accounts of part-of relation traditionally appear in formal ontology, where, as for any formal relation, it is taken to universally apply to all domains and therefore to be unique. Theories of this fundamental relation in this field are grouped under the term "mereology", coined by Lesniewski’s seminal work. (Lesniewski, 1927-31; Simons, 1987; Casati and Varzi, 1999)

\subsection{Part-whole relations in language are not just mereology}

In the standard theory (Simons, 1987), also called "classical mereology", the part-of relation, often noted P (or PP for the proper part-of relation) is a partial order, equipped with a fusion (sum) operator, and assumed to be extensional, i.e., no two different entities have the same proper parts.

As they are partial orders, P and PP are transitive. However, it has been pointed out long ago (Lyons, 1977; Cruse, 1986) that there are frequent cases of intransitivity of part-of relation as expressed in language. For instance,

(6) Marguerite's tail is part of Marguerite the cow, and Marguerite is part of the herd, but Marguerite's tail is not part of the herd; similarly,

(7) even if The house has a door and The door has a handle are true, The house has a handle cannot describe the same state of affairs (it evokes at best a toy house with a carrying handle on top). 
Additional features make classical mereology inadequate. The fusion operator being general, fusioning whatever entities makes up a new entity, and in particular, the fusion of any parts is itself a part. As a result, my left little finger plus my nose is "a" part of me, although this construct has no linguistic existence as a single entity, neither, arguably, conceptual existence. Extensionality too, is controversial. Starting with the same parts, one would like to distinguish several wholes, as it has been argued since Aristotle that Marguerite the cow is different from the mere collection of its organs.

Motivated especially by the intransitivity issue, and following Lyons's suggestion, several authors have explored the hypothesis of a multiplicity of part-whole relations.

\subsection{The multiple relation hypothesis}

The much cited article (Winston et al., 1987) distinguishes six relations, namely "component-integral object" (e.g., handle-cup), "membercollection" (e.g., tree-forest), "portion-mass" (e.g., slice-pie), "stuff-object" (e.g., steel-bike), "feature-activity" (e.g., paying-shopping), "place-area" (e.g., oasis-desert). This distinction is based on three binary parameters, described in terms of properties that are external to mereology: the "functional" role of the part with respect to the whole being supported or not by the specific spatial/temporal position of the part within the whole; the part and the whole being or not "homeomerous", that is, "similar" or "of the 
same kind"; and the part being "separable" from the whole or not. Each relation corresponds to a different combination of the three parameters. The paper argues that each of the six relations is transitive and that intransitivities occur when two different relations are mixed. For instance, the invalidity of argument in example (6) is due to the fact that it combines “component-integral object" and "member-collection". Although attractive, this thesis is too simple, as several relations are not themselves transitive: "member-collection" is never transitive, and (7) is usually taken to be an example of intransitivity of "component-integral object".

(Iris et al., 1988) examine dictionary data in which the term part or some of its synonyms (portion, piece, member...) appears. The authors conclude that it is necessary to distinguish four "models" or "schemata" of the part-whole relation: "functional component" (e.g., organ-body, engine-car), "segment" (e.g., slice-bread), "membership" (e.g., sheep-flock), and "subset" (as the authors focus on lexical classes rather than collections, the examples given for this case, e.g., tulip-flower, actually illustrate a taxonomic relation rather than a part-whole one). As far as transitivity is concerned, Iris et al. claim that neither "functional component" nor "membership" are transitive, but that "segment" and "subset" are. 


\subsection{The role of ontological distinctions among entities}

In the work just reported, especially in (Winston et al., 1987), there appears to be a pervasive parameter on which the distinctions between part-whole relations rely: the nature of the relata. Indeed, the terms themselves used by Winston et al. to designate their six relations, "object", "collection", "mass", "stuff", "activity" or "area", refer not so much to relations, but to kinds of entities. Exploiting the existing analyses of such kinds, studied both in formal ontology and in formal semantics, we propose to examine what in the part-whole relation(s) is specific to the ontological nature of the entities related. This study should result in the identification of the part-whole relations that it is legitimate to distinguish from the ontological and linguistic points of view.

There are two orthogonal dimensions of linguistically relevant ontological distinctions, one which we will call "number", and one which we will call "category".

\subsubsection{Number}

In French, English and many languages, number is marked in a regular way both by syntax (determiners, number proper) and in the lexicon (countable / uncountable terms, collective terms). Formal semantics, through the study of plural expressions has developed several theories of number. 
Classical analyses of plurals and groups (Landman 1996; Link, 1997) distinguish between atomic entities (atoms), which can be singular or collective, and plural entities (see also Muller's chapter in this volume). Any collective atomic entity, e.g., un groupe de garçons ('a group of boys'), un orchestre ('an orchestra') or un troupeau ('a herd'), is obviously "constituted of' some plural entity, e.g., John, Paul et Roy ('John, Paul and Roy'), les garçons ('the boys'), les musiciens ('the musicians'), or les vaches ('the cows"), which are "sums" of boy-atoms, musician-atoms, or cow-atoms. These classical theories of plurality are based on Boolean algebras with the null element removed, in other words, classical mereology. We have shown in (Vieu, 1991; Aurnague \& Vieu, 1993) that using a theory of plurality which builds on (Link, 1983) (see also Muller's chapter, this volume), the characterization of the relations of "Member-collection" and "Subcollection-collection" is immediate.

Member-collection is the relation that holds between a singular entity and either $^{3}$ a plural entity or a collection. It appears already in both (Winston et al., 1987) and (Iris et al., 1988), and is illustrated by the relation that may hold between une vache ('a cow') or la vache Marguerite ('Marguerite the cow') and either les vaches ('the cows') or le troupeau de vaches ('the herd of cows'), le Texas ('Texas') and les Etats-Unis ('the USA'), etc., as expressed by une de ces vaches ('a cow from these cows'), Marguerite fait partie de mon troupeau de vaches ('Marguerite is part of my herd of cows'), or Le Texas fait partie des Etats-Unis ('Texas is part of the USA'). It can be 
proven that this relation is not transitive, as illustrated by the counterexample Le Texas fait partie des Etats-Unis ('Texas is part of the USA') and Les Etats-Unis font partie de l'ONU ('USA is part of the UN') but Le Texas ne fait pas partie de l'ONU ('Texas is not part of the UN').

Subcollection-collection is the relation that holds between two plural entities —or collections constituted by such plural entities, all the atoms of the first being also atoms of the second. (Winston et al., 1987) doesn't consider it, and (Iris et al., 1988) appears to confuse it with the taxonomic relation "isa". Linguistic examples are not very numerous, but we can still hold that this relation is referred to by expressions such as: Le Benelux est dans l'Union Européenne ('The Benelux is in the European Union'), Le couple Dupont fait partie des gagnants ('The Dupont couple is part of the winners'), ${ }^{4}$ les pins de cette forêt ('the pines of this forest'). This relation is transitive, and we can also show that Member-collection and Subcollectioncollection give rise to a mixed transitivity, as illustrated by a case in which Marguerite fait partie de mon troupeau ('Marguerite is part of my herd'), mon troupeau fait partie du troupeau de toutes les vaches de mon village ('my herd is part of the herd of all cows in my village'), and thus Marguerite fait partie des vaches de mon village ('Marguerite is part of the cows of my village'):

$(M b-\operatorname{Coll}(x, y, t) \wedge \operatorname{Subcoll-Coll}(y, z, t)) \rightarrow \operatorname{Mb}-\operatorname{Coll}(x, z, t)$ 


\subsubsection{Categories}

Categories are expressed linguistically in a variety of ways. In many languages, syntax already encodes certain important distinctions: temporal (tense and aspect), spatial (pre- or post-positions, cases) or material (mass terms). Such distinctions often correspond to the "top-level" or fundamental categories in a formal ontology (Guarino, 1998). In the present work, we are using a set of "ontological categories" forming a coherent top-level ontology from a metaphysical and logical point of view and as faithful as possible to the semantic distinctions deeply encoded in languages.

Obviously, the lexicon covers a much larger range of distinctions, not all of them being relevant from a philosophical point of view, i.e., not prominent in an ontological analysis. The lexicon is often modeled as a taxonomy of "lexical types", for instance as in WordNet (Fellbaum, 1998). Such taxonomies can be improved from an ontological point of view using formal ontology methods (Welty \& Guarino, 2001) and in particular restructured according to a top-level ontology (Oltramari et al, 2002). Actually, a taxonomy is only the backbone of the lexicon, which needs to be given some flesh through the use of a large number of axioms and definitions, connecting linguistic conventions to ontological and, more generally, world knowledge. We will see in Section 4 that such a lexicon wealth and depth, with its taxonomy of lexical types, is essential for the analysis of part-whole relations. The notion of matter belongs to the ontological distinctions that in French and English are marked in syntax. In fact, mass terms and substance expres- 
sions have been studied extensively in formal semantics (see, e.g., Parsons, 1970, 1975; Pelletier \& Schubert, 1989), as well as in analytic philosophy (Quine, 1960), often using mereology as a theoretical basis (see also Muller's chapter, this volume). These studies have helped understand what is the relationship between an "amount of a substance" (de l'eau ('some water')) and the "substance" itself (l'eau ('water')), as well as the correspondences between substances and "material objects" denoted by count nouns as in, e.g., un gâteau ('a cake') / le gâteau ('cake'). The properties of being dissective or homeomerous (any part of an amount of water is an amount of water) and being cumulative (the mereological sum of two amounts of water is an amount of water) have been largely discussed, some authors retaining that they always hold from a linguistic point of view, others noting that dissectivity poses granularity problems (more conspicuously for mobilier ('furniture') than for eau ('water')). Let's note that the spatial property of connectedness also alters cumulativity, at least from a linguistic point of view: deux morceaux de bois ('two pieces of wood') usually don't make up un morceau de bois ('a piece of wood') and deux verres d'eau ('two glasses of water') is ambiguous between a single amount and a plural whose atoms are amounts.

As shown in (Vieu 1991; Aurnague \& Vieu, 1993), the use of three categories, "substance", "amount of a substance" and "material object", and a theory of amounts of substance based on Parson's, makes the formalization of two part-of relations, "portion-whole" ("portion-mass" in (Winston et al., 
1987), "segment" in (Iris et al., 1988)) and "substance-whole" ("stuffobject" in (Winston et al., 1987)), quite straightforward (see also Muller's chapter in this volume).

Portion-whole may hold between two amounts of the same substance, as in de l'eau de ce verre d'eau ('some water from this glass of water'), or between an amount of a substance and a singular entity which is constituted of an amount of the same substance, as in une tranche de ce gâteau ('a slice of this cake'). Portion-whole is transitive.

Substance-whole can link two amounts of different substances like in le sucre de ce verre de limonade ('the sugar in this glass of soda') or an amount of a substance and a singular entity which is constituted of an amount of different substance, as in la farine du gâteau ('the flour in the cake'). ${ }^{6}$ Again, Substance-whole is transitive.

Formal semantics, often coupled with ontological investigations, yields the identification of further categories. Time has been extensively studied in many languages as well as in formal ontology, and, as a result, several proposals for the subdivision of the "eventuality" category exist. The study of the semantics of French spatial expressions, in particular spatial prepositions (Aurnague \& Vieu, 1993) and "Internal Localization Nouns" (e.g., haut ('top'), bord ('edge'), coin ('corner'), centre ('center')) (Aurnague, 1996, 2004; Borillo, 1999), as well as the study of the Basque genitives (Aurnague, 2002), have shown the necessity to distinguish the categories of, again, "material object" (e.g., un gâteau ('a cake')), "geographical loca- 
tion", (un champ ('a field')) and "space portions" (l'espace sous la table ('the space under the table'), l'intérieur du verre ('the inside of the glass'), un trou ('a hole')).

In the remainder, we will focus on the category of material objects only. Indepth formal studies of the possibly specific ${ }^{8}$ part-whole relations between temporal entities (corresponding to "feature-activity" in (Winston et al., 1987)), geographical locations (corresponding to "place-area" in (Winston et al., 1987)) or space portions are left aside in this work and, to the best of our knowledge, remain yet to be done.

\subsubsection{The missing relations}

Restricting our investigation to the categories of "amount", "substance" and "material object" and taking into account the orthogonal numerical dimension, we have been able to define four relations: Member-collection, Subcollection-collection, Portion-whole and Substance-whole. However, even considering only material objects, the picture is not complete. The arguably most typical part-whole relation, the one involved in (1), (2) and (5), named "component-integral object" in (Winston et al., 1987) or "functional component" in (Iris et al., 1988), is missing. Although all these examples bear on material objects, this relation is apparently not directly dependent on the nature of the relata, as it rather focuses on a "functional link" between the part and the whole. Most descriptions point out that the part "plays a role" in the whole, and that both are conceived as "integral objects", i.e., as 
presenting a clear unity due to some specific "function" and as having definite "boundaries". However, existing analyses, including our own previous work, stop at this level of description without giving a deeper account of what exactly is the functional link between the part and the whole. With the objective to make a significant progress in the characterization of the semantics of the part-whole relations, the remainder of this paper is devoted to this relation, which we will call "component-integral whole"9 or CIW for short.

Before turning to the analysis of the functional aspects essentially involved in CIW, let's point out that there is still another part-whole relation between material objects. The relation involved in example (3) as well as in un morceau de la tasse ('a piece / shard of the cup') and l'avant de la voiture ('the front of the car') is not captured by any of the five ones we have listed. This relation, that we call "piece-whole", is linguistically expressed using relational nouns that mostly are Internal Localization Nouns. It is perhaps the relation that is the closest to the mere spatial inclusion, except that the part is spatially connected, and that part and whole are material objects. We have proposed in (Vieu, 1991; Aurnague \& Vieu, 1993) to define it on the basis of these properties, with an additional feature stating that there is no functional link, i.e., that "piece-whole" and CIW are disjoint relations, to account for the fact that components cannot be described by means of terms like morceau ('piece'). 


\section{Analysis of functionality}

The notion of function has been addressed in philosophy mainly with the objective of conciliating neo-Darwinism and the functional, teleological, talk widely used in biology (Allen et al. 1998). Although some authors have tried to extend their analysis of function in biology to a broader notion of function which would apply to artifacts as well, it is only recently that philosophers have dealt specifically with artifacts. In computer science, researchers have focused on the analysis of function in engineering. We will now quickly go through this literature to extract the key ideas to reuse, keeping one observation in mind. Even though language arguably makes a distinction between the natural and artificial realms in some occasions, ${ }^{10}$ and leaving aside the special case of animate entities and some of their body

parts, ${ }^{11}$ it can be claimed that most languages do not systematically distinguish CIW relations on organisms from those on artifacts and other inanimate entities. We will therefore look for a generic notion of functionality. This very remark allows us to immediately reject as dedicated exclusively to artifacts the definition of function proposed in (Dipert, 1993) for it is based on the intentions, deliberations and actions of the artifact's creator, and cannot therefore apply to organisms and their parts. ${ }^{12}$ It can be noted that, probably for this reason, other scholars consider that function and creator's intentionality are two separated notions, although they are both at play in the categorization of artifacts (Bloom, 1996). 
In philosophy of biology, the major trend is constituted by etiological approaches to functionality (see, e.g., Wright, 1973; Millikan, 1989). Function is there understood as the reason, or "purpose", why a given component is present in a given organism, and is analyzed in terms of a causal history of the ancestors of this organism. The "disposition" of the trait that contributed to the survival and reproduction of its ancestors explains the presence of the current trait in the organism. Extensions to function of artifacts have been suggested by their proponents themselves, but such approaches are discussed and shown to fail in (Vermaas \& Houkes, 2003); they appear in any case extremely complex and hardly applicable. We strongly doubt that the notion of function needed to account for the CIW relation makes necessarily reference to the causal history of a chain of items connected by some reproduction mechanism. On top of organisms and artifacts, CIW clearly applies to example (5) and other pairs of natural inanimate entities like an oxygen atom and a molecule of water, a planet and a solar system, a plate and the earth's crust, a pond and the hydrological system of some area, etc. for which no sort of etiological account makes any sense.

The philosophy of biology offers other solutions though, some authors rejecting the "backward-looking" notion of function to adopt a behavioral approach. The perspective is to explain how a component performs a function rather than why it is there. One of the most developed and famous account in this trend is that of (Cummins, 1975). Cummins proposes the following definition: 
"The function of $x$ in the system $s$ is to $\varphi$, relative to an analytical account $a$ of $s$ 's capacity to $\psi$ if and only if $x$ has the capacity to $\varphi$ in $s$, and $a$ accounts for $s$ 's capacity to $\psi$ by, in part, appealing to the capacity of $x$ to $\varphi$ in $s$." For instance, the function of a pigeon's wing with respect to some analytical account of the pigeon's capacity to fly is to generate lift and propulsion.

This approach appears to be much more suitable to our generic needs, as it can apply to organisms as well as all inanimate entities, including artifacts. Philosophy of biology meets clearly here engineering approaches to functionality, such as (Chandrasekaran, 1994), in which function is also essentially based on structural knowledge and on the behavior of components. In this work, behavior of components are taken to be "local", while functions are relative to the whole system. This is very similar to Cummins's distinction between function and capacity, the capacity of $\varphi$-ing being understood as a disposition, i.e., a regularity in behavior (when a certain type of event occurs, the entity which has the capacity of $\varphi$-ing systematically manifests its capacity, it is $\varphi$-ing), while a function is a capacity which contributes to the capacity of a more general system. The function of wholes makes reference to the "capacity" of some larger system comprising, for an artifact, the user or even some social system, and, for an organism, its community together with its ecological niche.

Defenders of etiological approaches (e.g., Millikan, 1989) have criticized the behavioral ones in that they miss out the normative aspects of functions, 
and are unable to attribute a function to a diseased organ or a broken component of an artifact. This is due to the fact that capacities are defined on the basis of regularities in behavior under certain conditions, considering only the behavior of the item considered, and not that of some "family" of items. They also point out that it is not trivial to fully characterize the "normal conditions" under which the regularities of behavior are supposed to be observed. In addition, we observe that Cummins's (as well as Chandrasekaran's) notion of function presupposes an analytical account of a system (or some structural knowledge of it). That is, it presupposes that the system is already decomposed into components and therefore assumes the very relation CIW that we would like to define on the basis of the notion of function. It seems then difficult to apply for our needs, as a definitional circularity would result. In fact, the same argument sheds some doubt on the behavioral analyses of function themselves, since their authors have apparently not paid much attention to what exactly are the notions of component and analytical system they are assuming. However, we do not want to propose here a new account of functionality in general; we just aim at capturing the functionality aspects involved in the semantics of the linguistic expressions of the CIW relation.

Even though we will retain some of the basic concepts of the behavioral approaches, our proposal departs somewhat from them. It could be related to Searle's, who considers that functions, be they of artifacts, of organisms and of inanimate natural entities, are not intrinsic as they are always "assigned" 
by an "observer" (Searle, 1995). We do not subscribe though to the bottom line of Searle's approach which is to assume teleology necessarily underlies function; we only consider that the normative aspects of function are attached to socially relevant categories of entities, namely the lexical types used to describe them. We will therefore (i) focus on the notion of function that does not only concern the actual entities at hand, but that is conventionally associated with the "types" of the entities as expressed by the lexical items used to denote them. ${ }^{13}$ And instead of making explicit reference to mental attitudes of some agents, to some causal history of a family of entities within a type, or to a previous behavioral-analytical account of the whole-type, we will more simply (ii) rely on a primitive notion of "functional dependence" between types to account for the normative links between the component and the whole.

\section{Function of entities "under a description"}

\subsection{Lexical types}

Let's first examine why the functions that we should take into account are not those of the entity considered with all its properties, but only those that are associated to the lexical type of the entity. We hold that the way the entity is described by a noun phrase filters out the properties, including the 
functions, that are relevant for the interpretation of natural language expressions, including those denoting the CIW relation. In other words, the function of the part and that of the whole, as well as the roles these functions play one with respect to the other, may be made apparent or not by the lexical items chosen, and the resulting expression may denote or not a CIW relation. To see this, consider the differences between the following genitive phrases and sentences:

(8) la tête du lit / ?la tête du meuble / ??la tête de l'artefact / *la tête $d u$ (morceau de) bois ('the bedhead / the head of the piece of furniture / the head of the artifact / the head of the (piece of) wood')

(9) Le moteur fait partie de la voiture / Le moteur fait partie du véhicule / ??Le moteur fait partie de l'artefact

('The engine is part of the car / The engine is part of the vehicle / The engine is part of the artifact')

(10) une plume du canari / une plume de l'oiseau / une plume de l'animal / ??une plume de l'organisme

('a feather of the canary / a feather of the bird / a feather of the animal / a feather of the organism')

In some cases, the difference in acceptation can simply be explained by a difference in denotation. Le lit ('the bed') and le (morceau de) bois ('the (piece of) wood') can arguably be considered as denoting different entities. Even though the literature in formal ontology on this topic is very large, a respectable position holds that the (amount of) wood constitutes the bed, but 
the wood is not a bed and the bed is not wood, as both have different identity criteria (Welty \& Guarino, 2001). This is the position we have taken above in our account of mass terms and the part-whole relations "Portionwhole" and "Substance-whole" (see also Muller's chapter in this volume). Matters are very different for the objects le lit ('the bed') and le meuble ('the piece of furniture', a countable noun in French), la voiture ('the car') and le véhicule ('the vehicle'). In those cases, we unquestionably have taxonomic relations between the corresponding categories, i.e., the bed is a piece of furniture and the car is a vehicle. We have categories of varying degrees of generality, but in each case, certainly the same entity.

So, if the denotations are exactly the same, why is it that la tête du lit ('the bedhead') is perfect while la tête du meuble ('the head of the piece of furniture') is at best awkward? It has been argued that the interpretation of the genitive involves the recovering of some linking relation from the terms used (Barker, 1995; Partee \& Borschev, 2003), and similarly, we hold that when an expression (not necessarily a genitive) may denote the relation CIW, this relation can be recovered only if its functional aspects can be inferred from the terms used in the expression. And since it is not typical for a meuble to have a tête (unlike to have a pied ('leg')), nor for a tête to be a part of a meuble, the functional relationship is not available, and the interpretation of the genitive phrase is difficult. Obviously, a discourse context in which the entity denoted by le meuble is known to be a lit makes the interpretation available: 
(11) Un très grand lit occupait toute la chambre. La tête du meuble, bizarrement ouvragée, attirait l'attention.

('A very large bed filled the room. The head of the piece of furniture, strangely carved, drew the attention.')

Another phenomenon is at work with the unacceptability of ??-rated expressions in examples (9-10) which use very generic descriptions, as l'artefact (the artifact) or l'organisme (the organism). It is certainly "typical" for an engine to be part of an artifact, and for feathers to be part of an organism, although the opposite is not true. But those generic lexical types, which correspond probably to ontological categories, ${ }^{14}$ do not belong to the basic level (Rosch, 1978). In a study confronting taxonomies and "partonomies", (Tversky, 1990) shows that it is unusual to describe such abstract entities by referring to their parts, so that the functional link may be difficult to recover. This could explain the data, but our analysis will not go any further in this respect in this paper.

We will therefore take into account in the semantics of CIW the "lexical types" of the entities. We achieve this in a manner similar to that of (Masolo et al., 2004) for dealing with roles and, more generally, concepts considered from a constructive perspective. In this way, CIW doesn't relate entities, but entities-as-a-lexical-type, i.e., entities from a given descriptive point of view. So doing, we base our analysis on the normativity of linguistic types and allow for mal-functioning entities; functionality is not inferred from the actual current properties of the entities at hand, but from those properties 
that they would have if the entities were fully "functioning-as-a-lexicaltype". Lexical types are reified, and are thus distinguished from the fundamental (top-level) ontological categories which are treated as unary predicates. Reifying lexical types enables us to predicate over them and establish dependency links between those types and their linguistic and socio-cultural context (Masolo et al., 2004). Obviously, our approach relies on a rich theory of lexical types. (Pustejovsky, 1995) and even more (Asher, this volume) show that a structured lexicon is possible, although our work here, as well as others (Hathout et al., 2003) tend to show that an even richer account, that integrates more distinctions between lexical types and larger amounts of world knowledge, is necessary (Thomason, 2003).

\subsection{Function}

Now, what is the notion of function associated to a lexical type X? Defining capacities associated with a lexical type requires characterizing what are the "normal conditions" under which a certain behavior is observed. To avoid this, we do not simply adapt the behavioral approach to lexical types. Instead of considering capacities, i.e., potential behavior, we concentrate on the actual performance of the function at a given time. In other words, we do not focus on "being functional" but on "being functioning". In addition, we want to characterize the full function, and not the local behavior. For instance, we do not consider as being functioning an engine switched on and 
"working" flawlessly, i.e., producing motion power, while detached from any machine; we want to describe as "being functioning as an engine", an engine working flawlessly within the larger system of some machine using its motion power.

We will therefore use the property of " $\mathrm{x}$ being functioning as a $\mathrm{X}$ at time $\mathrm{t}$ ", considering the functional behavior that entities are typically supposed to be able to show to be described as a $\mathrm{X}^{15}$ Of course, something can be described as a type at a given time (e.g., this entity is described or classified as an engine), and not being at that time actually behaving as entities of that type typically do (as if the engine is currently switched off), and even not being capable of behaving as that type (as if the engine is flawed or broken). Conversley, something can be functioning as a type, while not being actually described as that type: many large enough and strong enough boxes could be used as stools, tables, etc., without being classified as such; so, in focusing on "functioning as" rather than on "having the function of", we clearly depart from the classical approaches to function.

Two different predicates, $\mathrm{CF}(\mathrm{x}, \mathrm{X}, \mathrm{t})$ for "the entity $\mathrm{x}$ is classified as a $\mathrm{X}$ at time t" (Masolo et al., 2004) and Functioning(x,X,t) for "the entity $\mathrm{x}$ is functioning as a $\mathrm{X}$ at time $\mathrm{t}$ ", are then needed. CF covers a wider range of properties than Functioning does, as a lexical type $\mathrm{X}$ is not only characterized by function, but also by shape, size or matter etc. (see, e.g., Bloom, 1996). On the other hand, Functioning is not just a restriction of CF with respect to functional aspects, because it stresses the actuality of the manifestation of 
such functional aspects, while for CF their typicality and potentiality is enough. Aristotle referred to the fact that "a hand without the body is not a hand, except in an equivocal sense", adding that "all things are defined by their function and capacity, so that when they are no longer such as to perform their function they must not be said to be the same things, but to bear their names in an equivocal sense". Our approach is less demanding than Aristotle's: it allows for detached or malfunctioning hands to be "classified as a hand", while not "functioning as a hand".

We assume that "functioning as a X" could be defined for each lexical type $\mathrm{X}$, perhaps relying on different approaches for artifacts or biological entities, even though we do not attempt this here. In the remainder, we will consider only the inferential properties common to all instances of Functioning, that is, we will take Functioning as a primitive predicate.

\section{Functional dependence}

The predicate Functioning accounts for the expressed function of entities-as$\mathrm{a}-\mathrm{X}$, for which the literature shows the need to refer to some larger system. We have seen though that to avoid the circular reference to the CIW relation we need to abandon the original idea of the behavioral approach of a system with its analytical account. So, how to account for the functional links between parts and wholes involved in CIW? We will use what we will call 
"functional dependence", a special kind of generic dependence between the types $\mathrm{X}$ and $\mathrm{Y}$. Functional dependence between a part and a whole states that the part plays a role within the whole, but doesn't explain what exactly is this role. This yields a weaker notion of function than Cummins's, but we will see in the next section that it is already quite powerful.

Studying dependence between parts and wholes is certainly not a new idea, as it dates back at least to (Husserl, 1970). In formal ontology, mereological essentialism holds that parts are essential to their wholes (Chisholm, 1976), and many authors use the distinction between essential and non-essential parts (Simon, 1997; ch.7), as e.g., for a human, between its brain or its heart and one hair; the notion of "being essential" is based on that of existential dependence, either in its specific (brain) or generic (heart) form. In addition, the classical approach to the notion of unity of a whole is based on dependence relations between the parts (Simon, 1997; ch.9). In linguistics, the focus is rather on the dependence of the part with respect to the whole, since many lexical types describing components are relational nouns or more generally, syncategorematic nouns. ${ }^{16}$ For instance, tête ('head'), tige ('stem'), poignée ('handle'), all make an implicit reference to an including entity of some kind, and genitive constructions in which such nouns are the head usually refer to the CIW relation.

The functional link we are looking for, though, is not that of essential part or whole, for we want to account for the CIW between a hair and a human or between a handle and a door: humans and hairs can exist separately, ${ }^{17}$ just 
as handles can exist without doors and doors can exist without handles. What we need to consider is whether the entity-as-a-X which is the part (or the entity-as-a-Y which is the whole), to be functioning as a $\mathrm{X}(\mathrm{Y})$, requires the existence of some entity which is both classified as a $\mathrm{Y}(\mathrm{X})$ and functioning as a $\mathrm{Y}(\mathrm{X})$. For instance, the functional relationship in the CIW between a handle and a door refers to the generic dependence between handles and, not doors, but more generically, "objects that can be moved or used by hand", such that for an handle to be "functioning as a handle" there exists some object "functioning as an object that can be moved or used by hand", i.e., being moved or used by some hand at the time considered. Similarly, in the opposite direction, a car (in the sense of automobile), to be functioning as a car, requires the existence of a functioning engine. And it can be argued together with Aristotle that a hand (or a human hair) to be "functioning as a hand" requires that some human exists which is "functioning as a human".

Let's now see how such a functional dependence can be formally characterized.

\subsection{Generic functional dependence}

The most basic dependence relation is the one that holds between two individuals, namely specific existential dependence (Husserl, 1970; Simons, 1987, ch. 8; Fine, 1995). $\mathrm{x}$ is dependent on $\mathrm{y}$ if and only if necessarily the existence of $\mathrm{x}$ implies that of $\mathrm{y}$. The precise nature of the alethic modality 
and that of the existence predicate (the existential quantifier will obviously not do here) is certainly debatable, but here, modifying slightly the proposals of (Simons, 1987, ch.8), (Fine, 1995) and (Masolo et al. 2003), we will choose a S5 modality ${ }^{18}$ and a temporalized existence primitive:

$$
D(x, y) \equiv \square \forall t(E(x, t) \rightarrow E(y, t)) \wedge \neg x=y \wedge \diamond \exists t E(x, t) \wedge \neg \square \forall t E(y, t)^{19}
$$

The second, third and fourth atoms in this definition avoid trivial cases that make the first atom true, when $\mathrm{x}$ and $\mathrm{y}$ are equal, when necessarily $\mathrm{x}$ doesn't exist or when necessarily y always exists.

Using the "classified as" predicate CF as axiomatized in (Masolo et al. 2004), we further define generic existential dependence between types. It is important to note that in the axiomatization of $\mathrm{CF}$, classification implies existence, i.e., $C F(x, X, t) \rightarrow E(x, t)$.

$$
\begin{aligned}
& G D(X, Y) \equiv \square \forall x, t \quad(C F(x, X, t) \rightarrow \exists y(\neg y=x \wedge C F(y, Y, t))) \wedge \diamond \exists x, t \\
& C F(x, X, t) \wedge \neg \square \forall t \exists y C F(y, Y, t)
\end{aligned}
$$

It only remains to introduce the Functioning predicate in this formula to obtain generic functional dependence:

$$
\begin{aligned}
& G F D(X, Y) \equiv \square \forall x, t((C F(x, X, t) \wedge F \text { unctioning }(x, X, t)) \rightarrow \exists y(\neg y=x \wedge \\
& C F(y, Y, t) \wedge \text { Functioning }(y, Y, t))) \wedge \diamond \exists x, t \quad(C F(x, X, t) \wedge \text { Functio- } \\
& \operatorname{ning}(x, X, t)) \wedge \neg \square \forall t \exists y(C F(y, Y, t))
\end{aligned}
$$

We assume the following simple axioms on the primitive Functioning, where $\subseteq$ is the mereological part-of relation between times ${ }^{20}$ and Subtype is defined on CF: Subtype $(X, Y) \equiv \forall x, t(C F(x, X, t) \rightarrow C F(x, Y, t))$. 
(Functioning $\left.(x, X, t) \wedge t^{\prime} \subseteq t\right) \rightarrow$ Functioning $\left(x, X, t^{\prime}\right)$

$($ Functioning $(x, X, t) \wedge \operatorname{Subtype}(X, Y)) \rightarrow$ Functioning $(x, Y, t)^{21}$

On the basis of the properties of the modal operator $\square$ and these axioms, it can be proved that GFD is transitive, provided that $\mathrm{X}$ and $\mathrm{Z}$ are disjoint types (in terms of CF, i.e., $\operatorname{Disjoint}(X, Y) \equiv \neg \exists x, t(C F(x, X, t) \wedge C F(x, Y, t)))$, and that GFD propagates from types to supertypes, provided the supertype is not necessarily always instantiated.

(T1) $(G F D(X, Y) \wedge G F D(Y, Z) \wedge \operatorname{Disjoint}(X, Z)) \rightarrow G F D(X, Z)$

(T2) $G F D(X, Y) \wedge \operatorname{Subtype}(Y, Z) \wedge \neg \square \forall t \exists x(C F(x, Z, t)) \rightarrow G F D(X, Z)$

\subsection{Individual functional dependence}

The functional link involved in a CIW relation between an entity $\mathrm{x}$-as-a-X and an entity $y$-as-a-Y refers to the generic functional dependence between their lexical types $\mathrm{X}$ and $\mathrm{Y}$, but we need in addition to establish that the link holds precisely between $\mathrm{x}$ and $\mathrm{y}$. We thus now define "individual functional dependence", between a X-as-a-X and a y-as-a-Y at some time t:

$$
I F D(x, X, y, Y, t) \equiv G F D(X, Y) \wedge C F(x, X, t) \wedge C F(y, Y, t) \wedge \forall t^{\prime}\left(\left(t^{\prime} \subseteq t \wedge\right.\right.
$$

Functioning $\left.\left(x, X, t^{\prime}\right)\right) \rightarrow$ Functioning $\left.\left(y, Y, t^{\prime}\right)\right)$

IFD requires that $\mathrm{x}$ and $\mathrm{y}$ are respectively classified as a $\mathrm{X}$ and a $\mathrm{Y}$ at time $\mathrm{t}$, but it does not imply that $\mathrm{x}$ and $\mathrm{y}$ must be functioning (as a $\mathrm{X}$ and as a $\mathrm{Y}$ respectively) during all of time $\mathrm{t}$; the conditional only states that when $\mathrm{x}$ is functioning, y must be functioning as well. So a car can be individually 
functionally dependent on an engine even though it is at times parked with its engine off, or even if the engine is broken and the car cannot run. ${ }^{22}$ We have already noticed that a door could have or not a handle, and that a handle, to be functioning, requires not necessarily a door (there are handles for knifes, bags, etc.) but more generally, some "object that can be moved or used by hand", ${ }^{23}$ like, e.g., a door. Between a x-as-a-handle and a y-as-adoor there therefore is what we will call "indirect individual functional dependence", based on the generic functional dependence between "handle" and some other lexical type subsuming "door". "Indirect individual functional dependence" is thus defined:

$$
\operatorname{IIFD}(x, X, y, Y, t) \equiv C F(y, Y, t) \wedge \exists Z(\operatorname{Subtype}(Y, Z) \wedge \operatorname{IFD}(x, X, y, Z, t))
$$

Of course, we have as a theorem:

(T3) $\operatorname{IFD}(x, X, y, Y, t) \rightarrow \operatorname{IIFD}(x, X, y, Y, t)$.

\subsection{Formalizing Component-IntegralWhole}

We are now in position to define the CIW relation. There are four cases, according to the fact that the individual functional dependence is direct or not, and according to the sense of the generic functional dependence between the lexical types, i.e., either the part is dependent on the whole, or the whole is dependent on the part. In all cases, a CIW between $\mathrm{x}-\mathrm{as}-\mathrm{a}-\mathrm{X}$ and $\mathrm{y}-$ as-a- $\mathrm{Y}$ at time $\mathrm{t}$ requires that both $\mathrm{x}$ and $\mathrm{y}$ are material objects ${ }^{24}$ and that $\mathrm{x}$ is included in y during $\mathrm{t}^{25}$ 
$C I W$-direct $1(x, X, y, Y, t) \equiv \operatorname{Obj}(x) \wedge \operatorname{Obj}(y) \wedge P P(x, y, t) \wedge \operatorname{IFD}(x, X, y, Y, t)$

$C I W$-direct2 $(x, X, y, Y, t) \equiv \operatorname{Obj}(x) \wedge \operatorname{Obj}(y) \wedge P P(x, y, t) \wedge I F D(y, Y, x, X, t)$

$C I W$-indirect $1(x, X, y, Y, t) \equiv \operatorname{Obj}(x) \wedge \operatorname{Obj}(y) \wedge P P(x, y, t) \wedge \operatorname{IIFD}(x, X, y, Y, t)$

$C I W$-indirect2 $(x, X, y, Y, t) \equiv \operatorname{Obj}(x) \wedge \operatorname{Obj}(y) \wedge P P(x, y, t) \wedge I I F D(y, Y, x, X, t)$

Let's now see how several examples, already mentioned or not, distribute among the four cases:

CIW-direct1: cuff-sleeve, stem-plant, carburetor-engine, finger-hand, handarm, arm-body, hand-body, heart-circulatory system, nucleus-cell

CIW-indirect1: handle-door (with "objects that can be moved or used by hand" for type subsuming "door"), door-house (with "wall, enclosure, building, cupboard or vehicle" subsuming "house"), engine-car (with "machine" subsuming "car"), brick-wall (with "construction" subsuming "wall"), valve-carburetor (with "fluid-holding device" subsuming carburetor), feather-canary (with "bird" subsuming "canary")

CIW-direct2: wall-house, engine-car, electron-atom, atom-molecule, finger-hand, hand-arm, cell-heart, feather-canary

CIW-indirect2: heart-circulatory system (with "pump" subsuming "heart"), brick-wall (with "construction material" subsuming "brick")

These examples show that in many cases (engine-car, finger-hand, handarm, brick-wall, heart-circulatory system, feather-canary...) we have both a 
CIW-1 and a CIW-2, that is, the part depends on the whole and the whole depends on the part.

The existence of one CIW relation between two entities licenses the use of the corresponding genitive constructions (e.g., le carburateur du moteur ('the carburetor of the engine')) as well as of other part-whole descriptions (e.g., le carburateur fait partie du moteur ('the carburetor is part of the engine')). In addition, distinguishing different CIW relations allows us to make predictions about determinative compound nouns of the form Npart de Nwhole (Nwhole Npart / NPpart of Nwhole; e.g., un moteur de voiture ('a car engine')) or Nwhole à/avec Npart (Npart Nwhole / Nwhole with Npart; e.g., un bateau à moteur ('a motor boat'/'a boat with engine)) (Borillo, 1996; Bosredon \& Tamba, 1991). The predictions that can be made for each CIW relation can be stated as follows. ${ }^{26}$

When there is a direct dependence of the type of the "head noun" on that of the "modifier", the modifier adds no information with respect to the head noun, that is, the compound does not denote a proper subclass, and is thus ill-formed. So, if a CIW-direct1 relation holds between $\mathrm{x}$-as-a-X and y-as-a$\mathrm{Y}$ then the construction $N X$ de $N Y$ is ruled out: *un pétale de plante ('a plant petal'), *un carburateur de moteur ('an engine carburetor'), *un pouce de main ('a thumb of hand'), *une main de bras ('an arm hand'). Similarly, if a CIW-direct2 relation holds between $\mathrm{x}$-as-a-X and $\mathrm{y}$-as-a- $\mathrm{Y}$ then the construction $N Y$ à/avec $N X$ is ruled out: ${ }^{27} *$ une maison à/avec mur(s) ('a wall house'/'a house with wall(s)'), *une automobile à/avec moteur ('a motor 
automobile'/'an automobile with engine), *un atome à/avec électrons ('an electron atom'/'an atom with electrons'), *une main à/avec doigts ('a finger hand'/'a hand with fingers').

On the other hand, when the dependence is indirect, the modifier may contribute to specify a class of entities, provided that these entities are distinct enough from the rest of those denoted by the head noun, which is, indeed, often the case. So, if a CIW-indirect1 relation stands between $\mathrm{x}$-as-a-X and $\mathrm{y}$-as-a-Y, then the construction $N X$ de $N Y$ is often acceptable: une poignée de porte ('a door handle'), un moteur de voiture ('a car engine'), une valve de carburateur ('a carburetor valve'), une plume de canari ('a canary feather'). And if a CIW-indirect2 relation stands between $\mathrm{x}-\mathrm{as}-\mathrm{a}-\mathrm{X}$ and $\mathrm{y}$-as-a-Y, then the construction $N Y$ à/avec $N X$ is often acceptable: un ordinateur ?à/avec touchpad ('a touchpad computer'/'a computer with a touchpad'), un bateau à voile/moteur ('a sailing/motor boat'), un mur en/de $\operatorname{brique}(s)^{28}$ ('a brick wall').

These different predictions on the (un)acceptability of determinative compound nouns show that the four CIW relations distinguished above have a real linguistic — more precisely, semantic — ground. Further proof of their relevance is provided by the analysis of transitivity, a well-known elusive issue. 


\section{Transitivity}

\subsection{Is Component-IntegralWhole transitive?}

We have seen in Section 2 that opinions on the transitivity of CIW are varied. Example (7) has been given quite early in the literature as a counterexample (Lyons, 1977; Cruse, 1986; Iris et al., 1988). Nevertheless, (Winston et al. 1987) hold that each kind of part-whole relation is transitive, and since they do not distinguish different cases of CIW, they assume it is transitive. (Simons, 1987) as well as (Casati \& Varzi, 1999) suggest that according to the additional constraints that specific part-whole relations impose on top of the mere mereological relation, the relation may be transitive or not, but they do not analyze CIW any further.

Some authors, though, have focused on the fact that CIW is at times transitive and at times not. (Lyons, 1977) compares the two examples (7), reformulated below, and (12):

(7) The house has a door and the door has a handle but the house doesn't have a handle.

(12) The jacket has a sleeve, the sleeve has a cuff, and the jacket has a cuff.

(Cruse, 1986) tries to explain this difference on the basis of the notion of "functional domain": the functional domain of the handle is restricted to the door, while that of the cuff, by its embellishment role, encompasses the 
whole jacket. To explain similar cases, (Moltmann, 1997) introduces the somewhat related idea of contextualizing the notion of "integral whole". If, in a given "situation" $\mathrm{s}$ in which both $\mathrm{x}$ is part of $\mathrm{y}$ and $\mathrm{y}$ is part of $\mathrm{z}, \mathrm{y}$ (e.g., in (12), the sleeve) is not considered as an integral whole, then the inference goes through and $\mathrm{x}$ is part of $\mathrm{z}$ in $\mathrm{s}$. On the contrary, if $\mathrm{y}$ is considered as an integral whole in s (e.g., in (7), the door), the inference is blocked.

Such explanations are not totally satisfactory because, apart from the fact that it is not trivial to formally characterize the notions of functional domain, integral whole ${ }^{29}$ or situation, they appear to fail to explain examples in which the transitivity goes through:

(13) Le carburateur fait partie du moteur, le moteur fait partie de la voiture et le carburateur fait partie de la voiture. ('The carburetor is part of the engine, the engine is part of the car and the carburetor is part of the car.')

In (13), there is no obvious reason for a carburetor to have a functional domain including the car, nor for the engine to be a non-integral whole, or at least a "less" integral whole than a door in the situation in which the door is part of the house.

We follow Cruse and Moltmann in trying to acknowledge the fact that there are both cases of transitivity and cases of non transitivity of CIW, but propose a new account. Before getting into the details, let's observe that there is a simple way to turn example (7) into a case of transitivity: 
(7') The house has a door, the door has a handle, and the house has a door-handle (which is made of brass).

This observation confirms what we claimed in Section 4, namely that CIW holds when it is possible to recover from the terms used what is the functional link between the part and the whole. Here, changing "handle" in "door-handle" contributes to specifying what is the role of the handle with respect to the house, i.e., a component of a door, which is (assumed to be) a component of the house.

\section{2. (In)Transitivity of CIW revisited and other inferential properties}

On the basis of the transitivity of the mereological relation PP and the formal properties of the relations of functional dependence that we have introduced, in particular (T1), the following theorems can be proved:

(T4) $(C I W$-directl $(x, X, y, Y, t) \wedge C I W$-directl $(y, Y, z, Z, t) \wedge \operatorname{Disjoint}(X, Z))$

$\rightarrow C I W$-direct $1(x, X, z, Z, t)$

(T5) $(C I W$-direct2 $(x, X, y, Y, t) \wedge C I W$-direct2( $(y, Y, z, Z, t) \wedge \operatorname{Disjoint}(X, Z))$

$\rightarrow C I W$-direct2(x,X,z,Z,t)

(T6) $(C I W$-direct $1(x, X, y, Y, t) \wedge C I W$-indirectl $(y, Y, z, Z, t) \wedge \operatorname{Disjoint}(X, Z))$

$\rightarrow C I W$-indirectl $(x, X, z, Z, t)$

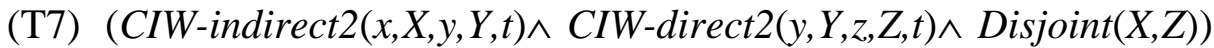

$\rightarrow C I W$-indirect2(x,X,z,Z,t) 
In contrast, the following formulas are not theorems:

(i) $\quad(C I W$-indirect $1(x, X, y, Y, t) \wedge C I W$-direct $1(y, Y, z, Z, t) \wedge \operatorname{Disjoint}(X, Z))$

$\rightarrow(C I W$-indirectl $(x, X, z, Z, t) \vee C I W$-indirect $2(x, X, z, Z, t))$

(ii) $\quad(C I W$-direct2 $(x, X, y, Y, t) \wedge C I W$-indirect2 $(y, Y, z, Z, t) \wedge \operatorname{Disjoint}(X, Z))$

$\rightarrow(C I W$-indirect $1(x, X, z, Z, t) \vee C I W$-indirect $2(x, X, z, Z, t))$

(iii) $(C I W$-direct $1(x, X, y, Y, t) \wedge C I W$-direct2 $(y, Y, z, Z, t) \wedge \operatorname{Disjoint}(X, Z))$

$\rightarrow(C I W$-indirect $1(x, X, z, Z, t) \vee C I W$-indirect $2(x, X, z, Z, t))$

(iv) $(C I W$-direct2 $(x, X, y, Y, t) \wedge C I W$-direct $1(y, Y, z, Z, t) \wedge \operatorname{Disjoint}(X, Z))$

$\rightarrow(C I W$-indirect $1(x, X, z, Z, t) \vee C I W$-indirect $2(x, X, z, Z, t))$

We can note at this point that the assumption of (Winston et al., 1987) that all part-whole relations are transitive, and that intransitivities occur when mixing different relations is again not confirmed by our analysis, even though we have distinguished four relations. Indeed, (T4-5) tell us that CIW-direct1 and CIW-direct2 are transitive (provided the lexical types $\mathrm{X}$ and $\mathrm{Z}$ are disjoint), but CIW-indirect1 and CIW-indirect 2 are not (because of $\neg(\mathrm{i}), \neg$ (ii) and (T3)). In addition, there are cases of "mixed" transitivities (T6-7).

So, because of (T6) we can explain why (12) and (13) are examples of transitivity of CIW, seen as a global relation: any cuff functionally depends on a sleeve, any sleeve functionally depends on a garment, e.g., a jacket, therefore any cuff functionally depends on a garment, e.g., a jacket; any carburetor functionally depends on an engine, any engine functionally depends on a 
machine, e.g., a car, therefore any carburetor functionally depends on a machine, e.g., a car. Similarly, (14) is an example of transitivity because of (T4), (15) because of (T5), and (16) because of (T7). ${ }^{30}$

(14) Ma main fait partie de mon bras, mon bras fait partie de mon corps, donc ma main fait partie de mon corps.

('My hand is part of my arm, my arm is part of my body, therefore, my hand is part of my body.')

(15) Cet électron fait partie de cet atome, cet atome fait partie de cette molécule, donc cet électron fait partie de cette molécule. ('This electron is part of this atom, this atom is part of this molecule, therefore, this electron is part of this molecule.')

(16) Cette brique fait partie de ce mur, ce mur est une partie de la maison, donc cette brique fait partie de la maison.

('This brick is part of this wall, this wall is part of the house, therefore, this brick is part of the house.')

On the other hand, because (i) is not a theorem (and because of (T3)), (7) and (17) are examples of non transitivity. As for (18), even though the dependence goes both ways for the second premise, since (ii) and (iv) are not theorems, the inference doesn't get through.

(17) One says: la valve du carburateur ('the carburetor valve') and le carburateur de la voiture ('the carburetor of the car'), but not ??la valve de la voiture ('the valve of the car'), nor ??La voiture 
a une valve ('The car has a valve') and not even ?? Cette valve fait partie de la voiture ('This valve is part of the car').

(18) Cette cellule fait partie du coeur ('This cell is part of the heart'), Le coeur fait partie du système circulatoire ('The heart is part of the circulatory system'), but not ??Cette cellule fait partie du système circulatoire ('This cell is part of the circulatory system').

Finally, let us note that our analysis can explain further inferential patterns, involved in the contrast between the first pairs of sentences of examples (810) —leaving aside the problem of referring to ontological categories such as those of artifacts and organisms. Even if $\mathrm{CF}$ is transitive and Functioning and GFD propagate from subtypes to types, the following combinations only yield theorems on CIW:

(T8) $C I W$-direct $1(x, X, y, Y, t) \wedge \operatorname{Subtype}(Y, Z) \wedge \neg \square \forall t \exists z(C F(z, Z, t)) \rightarrow$ $C I W-\operatorname{direct} 1(x, X, y, Z, t)$

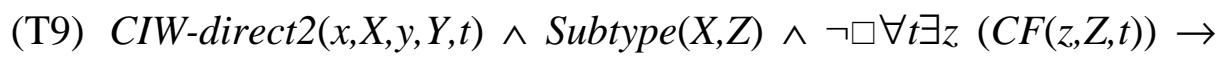
$C I W$-direct1 $(x, Z, y, Y, t)$

The other combinations, i.e., the following formulas, are not theorems:

(v) $\quad C I W$-directl $(x, X, y, Y, t) \wedge \operatorname{Subtype}(X, Z) \wedge \neg \square \forall t \exists z(C F(z, Z, t)) \rightarrow$ $C I W$-indirect $1(x, Z, y, Y, t)$

(vi) $\quad C I W$-indirectl $(x, X, y, Y, t) \wedge \operatorname{Subtype}(Y, Z) \wedge \neg \square \forall t \exists z(C F(z, Z, t)) \rightarrow$ $C I W$-indirect $1(x, X, y, Z, t)$ 


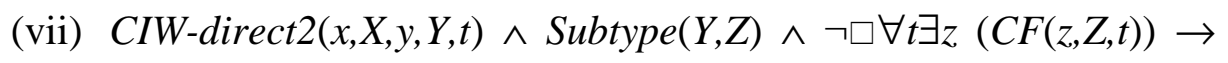
$C I W$-indirect2(x,X,y,Z,t)

(viii) $C I W$-indirect2 $(x, X, y, Y, t) \wedge \operatorname{Subtype}(X, Z) \wedge \neg \square \forall t \exists z(C F(z, Z, t)) \rightarrow$ $C I W$-indirect2( $x, Z, y, Y, t)$

(T8) suffices to explain that la plume de l'oiseau ('the bird's feather') in (10), which involves a CIW-direct1, can be described as la plume de l'animal ('the animal's feather'). On the other hand, since the relationships underlying the genitive expression la tête du lit ('the bedhead') in (8) are CIW-direct2 and CIW-indirect1 (with a very heterogeneous lexical type subsuming "lit" ('bed')), la tête du meuble ('the head of the piece of furniture') is unacceptable in most contexts. ${ }^{31}$ In example (9), Le moteur fait partie de la voiture ('The engine is part of the car') is still a case of CIWindirect1 (with "machine" ('machine') subsuming "voiture” ('car')) and CIW-direct2. What makes Le moteur fait partie du véhicule ('The engine is part of the vehicle') acceptable is the additional knowledge that all vehicles are machines, or that a functioning vehicle requires a functioning engine.

So, the notion of functional dependence goes a long way in explaining the behavior of CIW with respect to inferential patterns. Some puzzling cases remain, though. For instance, (19) should be an example of transitivity because it is an instance of both (T4) and (T5), but the consequent remains at best awkward.

(19) Le doigt fait partie de la main / un doigt de la main (gauche) / La main a un doigt ('The finger is part of the hand / a finger of the 
(left) hand / The hand has a finger'), La main fait partie du bras / la main du bras (gauche) / Le bras a une main ('The hand is part of the arm / the hand of the (left) arm / The arm has a hand'), ??Le doigt fait partie du bras / ??un doigt du bras (gauche) / ??Le bras a un doigt ('The finger is part of the arm / a finger of the (left) arm / The arm has a finger')

To explain the intransitivity of (19) in its "has a" version, Cruse argues that the relationship between the hand and the arm is an attachment and not a part-whole. But if the first version of the second sentence of (19), la main fait partie du bras, is fine, this explanation is hard to accept. However, it is certainly true that "bras" ('arm') — just as "jambe" ('leg') with "pied" ('foot') — ambiguously denotes either the whole limb including the hand or only the part of the body between the shoulder and the wrist. This ambiguity may explain the unacceptability of the third sentence in (19).

There are probably other problematic cases, and we cannot claim to have fully explored the meaning of CIW. The notion of function used here is perhaps too general and arguably weak, simply relying on a "functioning as" primitive predicate, very lightly axiomatized. The real "functional role" of the part within the whole, surely coming in different flavors according to the corresponding pair of lexical categories, remains unanalyzed in this proposal. On the other hand, what is proposed here can be useful to focus a future study of such functional role on relevant phenomena, eliminating the noise introduced by generic dependences in inferential patterns. 


\section{Conclusion}

We have shown in this paper that the analysis of part-whole expressions is largely dependent on both ontological categories and lexical types.

Our proposal to account for the Component-Integral Whole relation on the basis of functional dependence between lexical types is capable of explaining well-known puzzles regarding its inferential behavior, without the need to generically characterize function in a deep way.

There are nevertheless several issues regarding to what does or doesn't count as a CIW that are left open.

Regarding organisms, there is perhaps the need to distinguish CIW from the relation of "being a product of". For instance, bodily secretions (e.g., sweat), or even fruits on a tree are usually not considered as parts of the body or the tree, even though they arguably play a functional role in the organisms. It appears that the genesic (historic) dependence involved is more relevant in such cases than the functional dependence (Aurnague, 2004; Aurnague \& Plénat, 1996).

Regarding artifacts, similarly, the boundary between replaceable parts and consumables appears to be blurred: the role of the petrol in a car is conceptually distinguished from that of the brake fluid, for instance.

Finally, the distinction between attachments and non-essential components is also often not clear, and may change along with the evolution of concepts associated to lexical types. For instance, since a radio doesn't require to be 
part of a larger artifact to be considered as functioning, while cars are not conceptualized as typically requiring radios to be functioning as a car, the relationship between a radio and a car is not one of CIW as we have analyzed it. Of course, if the lexical type used is that of auto-radio ('car radio'), then, we have a functional dependence between the auto-radio and the car and therefore a CIW.

\section{Notes}

${ }^{1}$ This research was carried out within the project "Spatial entities and their categorization in language and cognition" (COG135; 1999-2001) that was financially supported by the Program "Cognitique" of the French Ministry of Research. We would like to thank Stefano Borgo, Carola Eschenbach, Giancarlo Guizzardi, Claudio Masolo, as well as two anonymous reviewers for their comments on a previous draft of this paper.

${ }^{2}$ In the case of French, let us, for instance, evoke attributive constructions with generic part nouns (e.g., Ce pignon est un composant du mécanisme ('This cogwheel is a component of the mechanism')), descriptions integrating spatial prepositions (e.g., Le cerveau est dans la tête ('The brain is in the head'), Le rétroviseur est à l'avant de la voiture ('The driving mirror is at the front of the car')) (Vieu, 1991; Vandeloise, 1986), Nwhole à Npart structures (e.g., un verre à pied ('a stemmed glass'), un stylo à plume ('a fountain pen')) (Borillo, 1996; Bosredon \& Tamba, 1991; see also below, Section 5.3), "composition" verbs (e.g., comporter/comprendre ('to be made/composed of', 'to consist of'), contenir ('to contain'), avoir/posséder ('to have'/'to own')), "assembling/pulling away” verbs (e.g., assembler ('to assemble'), réunir ('to gather'), découper ('to cut'), structurer ('to structure')) (Landelle, 1988) or "extraction/addition" verbs calling or not for particular deriva- 
tional processes (e.g., ôter/retirer ('to take out'/'to remove'), ébrancher ('to prune'), décapiter ('to behead'), plumer ('to pluck'), ajouter ('to add'), emperler ('to put pearls'), plâtrer ('to plaster')) (Aurnague \& Plénat, 1996; Gerhard, 1997).

${ }^{3}$ Even though the examples here don't seem to make much difference between a singular collection and a plural entity, the two have to be distinguished to account for surface syntactic number as well as complex distributivity and cumulativity behaviors with respect to predication. Such linguistic grounds converge with the metaphysical argument that collections involve some kind of unity criteria that mere sums lack (see Moltmann, 1997).

${ }^{4}$ This sentence is ambiguous between a reading in which the single winners are persons, in which case we do have a Subcollection-collection relation, and a reading in which the single winners are couples (like in a dance competition), in which case we only have a Member-collection relation.

${ }^{5}$ Substance reading, as in Le gâteau fait grossir ('Cake fattens').

${ }^{6}$ These definite descriptions make reference to the maximal amount of a certain substance in a whole. The relation Substance-whole actually applies to any amount of substance included in the whole.

${ }^{7}$ The object / location distinction is, from a most general point of view, contextual: any entity classified as a material object can (e.g., during a game) play the role of a "landmark" and temporarily be handled as a location, i.e., as spatially fixed in some frame of reference, in spite of its potential mobility in a larger environment. As a result, in formal ontology, "location" should be considered as a subcategory of "material object" or even not considered as a category at all because of this context sensitivity. But since the terrestrial frame of reference is permanently available for the description of most of our activities, the more specific "geographical location" can be considered as a separate category, and it is in fact encoded so in many languages. It is on this basis only that we can account for the French 
preposition $\grave{a}$ (Vandeloise, 1988) and Basque genitives; the semantics of Basque genitives also requires "mixed entities" object•geographical location (Aurnague, 2002, 2004; see also Asher's chapter in this volume).

${ }^{8}$ One can notice here that we are assuming a "segregation principle" (Vieu, 1991) that is implicitly or explicitly widely accepted in linguistics (Kleiber, 1999): a part-whole relation cannot relate two entities of two disjoint fundamental ontological categories. For instance, neither the substances l'eau (water) and le bois (wood) nor the material objects la mer (the sea) and le bateau (the boat) can be part of the event la régate (the regatta); only events can be part of events. Note that some examples of portion-whole and substance-whole apparently relate an amount and an object, but the analysis shows that they always involve two amounts.

${ }^{9}$ This relation was named "component-assembly" in our earlier work, but we felt that "assembly" preferentially referred to the sub-category of artifacts.

${ }^{10}$ This is the case of French derivative verbs calling for the prefix -é (e.g., ébrancher ("to prune'), écosser ('to shell'), égoutter ('to wring out, to drain')) which mainly apply to natural entities or "rough" artifacts (e.g., canvas) (Aurnague, 2004; Aurnague \& Plénat, 1995). ${ }^{11}$ Compare: ??Les poumons sont dans le (corps du) chat ('The lungs are in the cat('s body)') and Les poumons sont dans le thorax du chat ('The lungs are in the cat's thorax).

${ }^{12}$ Dipert actually suggests at some point that his approach could be adequate for organisms as well, based on an alleged necessity of our cognition to conceive function in terms of intentions, although no detailed proposal is actually made in this direction.

${ }^{13}$ This move appears to fit with cognitive psychology studies that show that categorizing an artifact under type $\mathrm{X}$ relies on (the recognition of) the creator's intention of making an entity of type X, rather than making an entity having a given "objective" function (Bloom, 1996). 
${ }^{14}$ We leave for a future paper the issue of whether and how language draws the line between fundamental ontological categories and lexical types, and in that case, how to deal with the lexical perspective given by terms arguably referring to such categories (e.g., entity, organism, or artifact).

${ }^{15}$ We want to point at a weakness of this proposal that arises if one needs to take into account complex functions. It is very unlikely that a Swiss knife displays at a same time all dispositions that it has to possess for it to fall under the description "a Swiss knife". Similarly, birds don't fly and lay eggs simultaneously. In addition, defining expected behavior may be difficult. I can consider that my car is properly working while its CD player is off or even broken; the issue is less clear when I'm driving with a flat tire, although I'm still being transported by the car. "Functioning as" surely requires further investigations, and the proposal further refinements.

${ }^{16}$ Generic part names like partie ('part') or composant ('component') and Internal Localization Nouns are truly relational nouns, just as husband, sister or gift are: their denotation directly involves a (binary or ternary) relation and they are necessarily (perhaps elliptically) modified by a possessive or a genitive (de Bruin \& Scha, 1988; Barker 1995; Partee \& Borschev, 2003). No similar syntactic-semantic property exists for the dependence of the whole on the part, and the literature ignores "whole names". Most part names (e.g., handle, feather) are not relational nouns, though; they nevertheless belong to the class of syncategorematic nouns (Kleiber, 1999), which make reference to some dependence relation in their semantics.

${ }^{17}$ A hair can exist even when no animal and no human exists any longer. There is no existential dependence, although there is a "genesic dependence", a kind of "historic dependence". 
${ }^{18}$ With or without the Barcan formula is not important, since what we need to prove our theorems is the Barcan converse, which we have anyway.

${ }^{19}$ The language used is a sorted first-order logic with one modality. Uppercase letters are variables ranging over reified categories, and lowercase letters over standard individuals. $\equiv$ is the syntactic relation of definition.

${ }^{20}$ We assume extended times (intervals or sums of intervals). Any version of mereology is adequate for parthood on times. Only the concern of not making unnecessary assumptions justifies the use of $\subseteq$ instead of the general mereological relation (see Note 25).

${ }^{21}$ This axiom should be adapted to deal with typicality and non-monotonicity correctly. For instance to accommodate the existence of penguins, if functioning as a bird means flying. ${ }^{22}$ This account of functional dependence is in principle not restrictive enough, since if $\mathrm{x}$ is flawed and never functions as a $\mathrm{X}$ during $\mathrm{t}$, the conditional is true for any $\mathrm{y}$. Some kind of causal connection between $\mathrm{x}$ and $\mathrm{y}$ is missing. However, for our purposes, the definition of CIW, a connection will be partially guaranteed by a mereological relation $\mathrm{P}$ between $\mathrm{x}$ and y. This is not a causal connection, but it excludes most irrelevant entities.

${ }^{23}$ It appears here that, in a given language, the lexicon may require more lexical types to express its semantic interrelationships than are actually lexicalized.

${ }^{24}$ We have focused here only on the case of CIW between objects. If, after further studies, it turns out that our analysis is also valid for "functional" part-of relations between geographical locations (an oasis and a desert), substances (water and milk), eventualities (a battle and a war), or even space portions (the inside of the drawer and the inside of the closet), then to account for the category segregation of part-whole relations, we could simply replace the first two atoms by Same-Category $(\mathrm{x}, \mathrm{y})$.

${ }^{25}$ We use mereology for modeling spatial (or spatio-temporal) inclusion, without any additional "parthood" flavour. $\mathrm{PP}(\mathrm{x}, \mathrm{y}, \mathrm{t})$ means the extension of $\mathrm{x}$ is strictly included in that of $\mathrm{y}$ 
during t. According to generic assumptions on the spatio-temporal of concrete individuals, a $3 \mathrm{D}$ or a $4 \mathrm{D}$ version of a (possibly non-extensional) mereology or mereotopology can be used. In our past work, we have been using a 4D version; see also Muller's chapter in this volume.

${ }^{26}$ It can be noted that these predictions heavily depend on the lexicon structure of each language and the approach adopted here consisting in formalizing functional dependences via lexical types seems to be well suited for grasping these differences. Among those peculiarities, let us highlight that the French noun doigt ('finger', 'toe') can apply to both hands and feet whereas pouce (thumb) is exclusive for hands, and that the English handle can identify a larger variety of parts (of objects that can be moved or used by hand) than the French terms manche, poignée, anse or queue which are restricted to narrower categories.

${ }^{27}$ Constructions calling for $\grave{a}$ are more grammaticalized than those calling for avec, giving rise to real compound nouns (Borillo, 1996; Bosredon \& Tamba, 1991). This is probably the reason for which in these examples the constructions with $\grave{a}$ sound even less acceptable than the constructions with avec.

${ }^{28}$ When the integrated whole is constituted by a collection of functional components of a same type, the prepositions en ('in') or de ('of') are used instead of à/avec: NY en/de NX.

${ }^{29}$ (Simons, 1987) proposes for instance to rely on some dependence relation between the parts to define an integral whole as a maximum sum of interdependent entities. With such a definition, simply no integral whole can be part of another integral whole.

${ }^{30}$ See the classification of examples in Section 5.3 for the clarification of the premises.

${ }^{31}$ In a context in which the piece of furniture is known to be a bed, the anaphoric resolution procedure should be extended to cover the substitution of the lexical types within the CIW relation. 


\section{References}

Allen, Colin, Mark Bekoff \& George Lauder (Eds.) (1998). Nature's Purposes. Analyses of Function and Design in Biology. Cambridge (MA) \& London: MIT Press.

Aurnague, Michel (1996). Les noms de localisation interne : tentative de caractérisation sémantique à partir de données du basque et du français. $\mathrm{Ca}$ hiers de Lexicologie, 69(2), 159-192.

Aurnague, Michel (2002). Relations de partie à tout, configurations typiques et dépendances : analyse sémantique de quelques constructions génitives du basque. Revue de Sémantique et Pragmatique, 11, 69-85.

Aurnague, Michel (2004). Les structures de l'espace linguistique : regards croisés sur quelques constructions spatiales du basque et du français. Leuven: Peeters.

Aurnague, Michel \& Marc Plénat (1996). La préfixation en é- et la relation de partie à tout. In D. Genthial et al. (Eds.), Actes du Séminaire Lexique : représentations et outils pour les bases lexicales, morphologie robuste (4352). Grenoble: CLIPS-IMAG.

Aurnague, Michel \& Laure Vieu (1993). A three-level approach to the semantics of space. In C. Zelinski-Wibbelt (Ed.), Semantics of Prepositions: 
From Mental Processing to Natural Language Processing [Natural Language Processing, 3] (393-439). Berlin: Mouton de Gruyter.

Barker, Chris (1995). Possessive Descriptions. Stanford, CA: CSLI Lecture Notes.

Bloom, Paul (1996). Intention, history, and artifact concepts. Cognition, 60, $1-29$.

Borillo, Andrée (1996). La relation partie-tout et la structure [N1 à N2] en français. Faits de Langue, 7, 111-120.

Borillo, Andrée (1999). Partition et localisation spatiale : les Noms de Localisation Interne. Langages, 136, 53-76.

Bosredon, Bernard \& Irène Tamba (1991). Verre à pied, moule à gaufres : préposition et noms composés de sous-classe. Langue Française, 91, 40-55. de Bruin, Jos \& Remko Scha (1988). The Interpretation of Relational Nouns. In 26th Annual Meeting of the ACL (25-32). Buffalo, NY: Association for Computational Linguistics.

Casati, Roberto \& Achille Varzi (1999). Parts and Places - The Structures of Spatial Representation. Cambridge, MA: MIT Press.

Chandrasekaran, Balakrishnan (1994). Functional Representation and Causal Processes. Advances in Computers, 38, 73-143.

Chisholm, Roderick (1976). Person and Object. London: Allen \& Unwin. Cruse, Alan (1986). Lexical semantics. Cambridge: Cambridge University Press. 
Cummins, Robert (1975). Functional Analysis. Journal of Philosophy, 72, 741-765. Reprinted in (Allen et al., 2003: 169-196).

Dipert, Randall (1993). Artifacts, Art Works, and Agency. Philadelphia: Temple University Press.

Fellbaum, Christiane, ed. (1998). Wordnet. An Electronic Lexical Database Cambridge, MA: MIT Press.

Fine, Kit (1995). Ontological Dependence. Proceedings of the Aristotelian Society, 95, 269-90.

Gerhard, Francine (1997). Dérivés verbaux préfixés par dé- dit négatif et relations partie-tout. Verbum, 3, XIX, 309-320.

Guarino, Nicola (1998). Some Ontological Principles for Designing Upper Level Lexical Resources. In A. Rubio, N. Gallardo, R. Castro \& A. Tejada (Eds.), First International Conference on Language Resources and Evaluation (527-534). Paris: European Language Resources Association.

Hathout, Nabil, Marc Plénat \& Ludovic Tanguy (2003). Enquête sur les dérivés en -able. Cahiers de Grammaire, 28, 49-90.

Husserl, Edmund (1970). Logical investigations. London: Routledge. Iris, Madelyn Anne, Bonnie E. Litowitz \& Martha Evens (1988). Problems of the part-whole relation. In M. Evens (Ed.), Relational models of the lexicon: Representing knowledge in semantic networks (261-288). Cambridge: Cambridge University Press. 
Kleiber, G. (1999). Anaphore associative et relation partie-tout: condition d'aliénation et principe de congruence ontologique. Langue Française, 122, 70-100.

Landelle, Martine (1988). Analyse syntaxique de l'expression de la segmentation dans le lexique français. D.E.A. report. Toulouse: Université de Toulouse-Le Mirail.

Landman, Fred (1996). Plurality. In S. Lappin (Ed.), Handbook of Contemporary Semantics (425-457). Oxford: Blackwell.

Lesniewski, Stanislaw (1927-1931). O podstawach matematyki [On the Foundations of Mathematics]. Przeglad Filosoficzny [Philosophical Review], 30-34. English translation in: Topoi, 2, 7-52.

Link, Godehard (1983). The logical analysis of plurals and mass terms: A lattice theoretical approach. In R. Bäuerle, C. Schwarze \& A.v. Stechow (Eds.), Meaning, use and interpretation of language (302-323). Berlin: de Gruyter.

Link, Godehart (1997). Algebraic Semantics in Language and Philosophy. Stanford, CA: CSLI Lecture Notes.

Lyons, John (1977). Semantics. Cambridge: Cambridge University Press. Masolo, Claudio, Stefano Borgo, Aldo Gangemi, Nicola Guarino, \& Alessandro Oltramari (2003). The WonderWeb Library of Foundational Ontologies and the DOLCE ontology (WonderWeb (EU IST Project 2001-33052) Deliverable D18.

Masolo, Claudio, Laure Vieu, Emmanuele Bottazzi, Carola Catenacci, Ro- 
berta Ferrario, Aldo Gangemi, \& Nicola Guarino (2004). Social Roles and their Descriptions. In D. Dubois \& C. Welty (Eds.), Knowledge Representation and Reasoning, KR2004 (267-277). Menlo Park, CA: AAAI Press.

Millikan, Ruth Garrett (1989). In Defense of Proper Functions. Philosophy of Science, 56, 288-302. Reprinted in (Allen et al., 1998: 275-312).

Moltmann, Friederike (1997). Parts and Wholes in Semantics. Oxford: Oxford University Press.

Oltramari, Alessandro, Aldo Gangemi, Nicola Guarino, \& Claudio Masolo (2002). Restructuring WordNet's Top-Level: The OntoClean approach. In OntoLex'2 workshop, LREC2002 (17-26). Paris: European Language Resources Association.

Parsons, Terence (1970). An analysis of mass terms and amount terms. Foundations of language, 6, 363-388.

Parsons, Terence (1975). Afterthougths on mass terms. Synthese, 31, 517521.

Partee, Barbara \& Vladimir Borschev (2003). Genitives, relational nouns, and argument-modifier ambiguity. In E. Lang, C. Maienborn \& C. Fabricius-Hansen (Eds.), Modifying Adjuncts (67-112). Berlin: Mouton de Gruyter.

Pelletier, Francis J. \& Lenhart Schubert (1989). Mass expressions. In D. Gabbay \& F. Guenthner (Eds.), Handbook of philosophical logic, vol. IV (327-407). Dordrecht: Reidel. 
Pribbenow, Simone (1995). Modelling physical objects: reasoning about different kinds of parts. In P. Amsili, M. Borillo \& L. Vieu (Eds.), Time, Space and Movement: meaning and knowledge in the sensible world (Part C, 31-44). Toulouse: LRC.

Pustejovsky, James (1995). The generative lexicon. Cambridge, MA: MIT Press.

Quine, Willard V. (1960). Word and object. Cambridge, MA: MIT Press.

Searle, John (1995). The Construction of Social Reality. New York: The Free Press.

Rosch, Eleanor H. (1978). Principles of Categorization. In E.H. Rosch \& B. Lloyd (Eds.), Cognition and Categorization (27-48). Hillsdale: Laurence Erlbaum.

Simons, Peter (1987). Parts - A study in ontology. Oxford: Clarendon Press. Tamba, Irène (1994). Un puzzle sémantique : le couplage des relations de tout à partie et de partie à tout. Le Gré des Langues, 7, 64-85.

Thomason, Richmond H. (2003). Non-monotonic formalisms for natural language semantics. In Proceedings of the Second International Workshop on Semantics, Pragmatics, Rhetoric (4-19). Donostia/San Sebastián: ILCLI. Tversky, Barbara (1990). Where Partonomies and Taxonomies Meet. In S.L. Tsohatzidis (Ed.), Meanings and Prototypes: Studies in Linguistic Categorization. NewYork: Routledge.

Vandeloise, Claude (1986). L'espace en français : sémantique des prépositions spatiales. Paris: Seuil. 
Vandeloise, Claude (1988). Les usages spatiaux statiques de la préposition à. Cahiers de lexicologie, 53, 119-148.

Vermaas, Pieter \& Wybo Houkes (2003). Ascribing Functions to Technical Artefacts: A Challenge to Etiological Accounts of Functions. British Journal for the Philosophy of Science, 54(2), 261-289.

Vieu, Laure (1991). Sémantique des relations spatiales et inférences spatiotemporelles: une contribution à l'étude des structures formelles de l'espace en langage naturel. Doctoral dissertation. Toulouse: Université Paul Sabatier.

Welty, Chris \& Nicola Guarino (2001). Supporting Ontological Analysis of Taxonomic Relationships. Data and Knowledge Engineering, 39(1), 51-74. Winston, Morton E., Roger Chaffin \& Douglas Herrmann (1987). A taxonomy of part-whole relations. Cognitive Science, 11, 417-444.

Wright, Larry (1973). Functions. Philosophical review, 82, 138-168. Reprinted in (Allen et al. 1998: 51-78). 